\title{
Conhecimento etnoherpetológico em diferentes gerações no Município de General
}

\section{Carneiro, Paraná}

\author{
Ethnoherpetological knowledge in different generations in the Municipality of General Carneiro, \\ Paraná
}

Conocimiento etnoherpetológico en diferentes generaciones en el Municipio de General Carneiro, Paraná

Recebido: 06/08/2021 | Revisado: 11/08/2021 | Aceito: 13/08/2021 | Publicado: 16/08/2021

\author{
Cezar Paulo Pereira Carneiro \\ ORCID: https://orcid.org/0000-0002-3075-5493 \\ Universidade Estadual do Paraná, Brasil \\ E-mail: cezarpcarneiro22@gmail.com \\ Henrique José Schipanski \\ ORCID: https://orcid.org/0000-0002-6012-6954 \\ Universidade Federal do Paraná, Brasil \\ E-mail: henrique.schipanski@gmail.com \\ Huilquer Francisco Vogel \\ ORCID: https://orcid.org/0000-0002-3993-7824 \\ Universidade Estadual do Paraná, Brasil \\ E-mail: huilquer@unespar.edu.br
}

\begin{abstract}
Resumo
O conhecimento popular envolvendo mitos e crendices sobre répteis e anfíbios existe há muito tempo na sociedade. Desta maneira, estudos etnoherpetológicos atuam como ferramenta para entender a relação entre a sociedade e esses animais. Este trabalho objetivou verificar como o conhecimento herpetológico empírico, mitos e crendices estão sendo repassados entre as diferentes gerações (populacionais) e verificar se há influência do nível de escolaridade nas percepções sobre aspectos etnoherpetológicos. O levantamento de dados foi realizado no município de General Carneiro, Paraná, no primeiro semestre de 2018, abordando três grupos de 30 pessoas (a saber: faixa etária I = 15 a 20 anos, II $=40$ a 45 anos e III $=65$ anos ou mais). A obtenção das informações foi através de questionário fechado embasado em uma lista de tópicos previamente escolhidos. Com a aplicação do teste de Kruskal Wallis obteve-se uma diferença de escores de conhecimento significativa entre as medianas da amostra (diferentes faixas etárias) analisadas. Assim, foi constatada uma diminuição gradativa da aceitação de crenças e mitos entre as três gerações analisadas, corroborando a hipótese de que a escolaridade vem contribuindo como um fator preponderante para uma compreensão da real representatividade desses animais no meio ambiente.
\end{abstract}

Palavras-chave: Etnozoologia; Herpetologia; Educação ambiental.

\begin{abstract}
The popular knowledge involving myths and beliefs about reptiles and amphibians have being for a long time in society. In this way, ethnoherpetological studies act as a tool to understand the relationship between society and these animals. This work aimed to verify how empirical herpetological knowledge, myths and beliefs passed on to different generations and to verify if there is some influence of the education level on the perceptions about ethnoherpetological aspects. The data collection was carried out in the city of General Carneiro, Paraná, in the first semester of 2018 year, addressing three groups of 30 people (namely: $\mathrm{I}=15$ to 20 years, II $=40$ to 45 years and III $=65$ years or more). The information was obtained through interviews with a closed questionnaire based on a list of previously chosen topics. With the application of the Kruskal Wallis test, a significant difference was found between the sample medians (different age groups) analyzed. Thus, a gradual decrease in the acceptance of beliefs and myths among the three generations was verified, corroborating with the hypothesis that schooling has been contributing as a preponderant factor to an understanding of the real representativeness of these animals in the environment. Keywords: Ethnozoology; Herpetology; Environmental education.
\end{abstract}

\section{Resumen}

El conocimiento popular que involucra mitos y creencias sobre reptiles y anfibios existe desde hace mucho tiempo en la sociedad. De esta forma, los estudios etnoherpetológicos actúan como una herramienta para comprender la relación entre la sociedad y estos animales. Este trabajo tuvo como objetivo verificar cómo se están transmitiendo los conocimientos, mitos y creencias herpetológicos empíricos entre diferentes generaciones (población) y verificar si 
existe una influencia del nivel educativo en las percepciones de los aspectos etnoherpetológicos. La encuesta de datos se realizó en el municipio de General Carneiro, Paraná, en el primer semestre de 2018, abarcando tres grupos de 30 personas. (a saber: grupo de edad I $=15$ a 20 años, $\mathrm{II}=40$ a 45 años y III $=65$ años o más). La información se obtuvo a través de un cuestionario cerrado basado en una lista de temas previamente elegidos. Con la aplicación de la prueba de Kruskal Wallis se obtuvo una diferencia significativa en las puntuaciones de conocimiento entre las medianas de la muestra (diferentes grupos de edad) analizados. Así, se constató una paulatina disminución en la aceptación de creencias y mitos entre las tres generaciones analizadas, corroborando la hipótesis de que la educación ha venido contribuyendo como un factor importante a la comprensión de la representación real de estos animales en el medio.

Palabras clave: Etnozoología; Herpetología; Educación ambiental.

\section{Introdução}

A etnociência é o estudo do conhecimento cultural que engloba diferentes disciplinas, como exemplo, Astronomia, Biologia e Zoologia (Sturtervant, 1964; Werner, 1972). Emergindo dessas disciplinas específicas, a etnozoologia é uma disciplina híbrida que se estruturou com elementos das ciências sociais e naturais, e nesse sentido busca entender como diferentes culturas entenderam e interagiram com a fauna ao longo do tempo (Alves \& Silva-Souto, 2015; Alves 2017; Alves et al., 2018). Essa disciplina pode ser subdividida em subdisciplinas que se preocupam com táxons específicos como exemplo a etnoherpetologia que busca entender a relação de humanos com anfíbios e répteis (Alves, 2017).

O conhecimento de mitos e crendices relacionados aos répteis e anfíbios desperta nas pessoas receios e temores, fazendo com que esta percepção empírica seja repassada de geração para geração como forma de autoproteção contra estes animais (Cardoso et al., 2010; Alves et al., 2014). Dessa maneira, a percepção popular de que sapos e serpentes são perigosos, acabam contribuindo para uma maior hostilidade contra estes animais (Moura et al., 2010). Neste contexto, faz-se necessário desfazer mitos e crendices que penalizam estes grupos de animais, enfatizando sua importância ecológica, comportamentos e a beleza de suas características fenotípicas (Crespo, 2012).

Trabalhos realizados acerca dos conhecimentos populares, visando compreender o conhecimento que a comunidade possui a respeito da fauna e da flora são de grande importância para elucidar quais fatores sociais e culturais, também são determinantes na relação do homem com a fauna e a flora (Mourão \& Nordi, 2006; Moura et al., 2010).

Com base nos aspectos citados anteriormente, o ensino de zoologia nas escolas pode atuar como uma importante ferramenta para proporcionar os conhecimentos corretos, sendo atuante durante a formação dos discentes desde as séries iniciais do Ensino Fundamental quando os animais são apresentados no começo da alfabetização científica; até o Ensino Médio, onde seu estudo torna-se mais complexo, a fim de promover o conhecimento científico e sensibilizar os estudantes acerca da importância da preservação da herpetofauna (Santos \& Terán, 2013).

Nesse sentido, um estudo feito por Moura et al. (2010) sobre o relacionamento entre pessoas e serpentes no leste de Minas Gerais, obteve-se uma relação mais pacífica e um maior conhecimento acerca desses animais em entrevistados com maiores índices de escolaridade e de menor faixa etária. Assim, tais estudos são importantes ferramentas para educação ambiental e avaliação sobre o impacto da educação recente sobre a percepção da biodiversidade.

Baseando-se na premissa que atualmente a acessibilidade à informação é maior para as gerações atuais, este trabalho testou se o grau de conhecimento herpetológico popular envolvendo mitos e crendices é o mesmo entre distintas gerações da população na região específica de General Carneiro-PR. Assim, hipotetizou-se que a escolarização mais recente possui maior grau de consciência ecológica. Finalmente, foi verificado se a escolaridade atua favorecendo a diminuição da aceitação de mitos e crendices.

\section{Metodologia}

O presente trabalho tem natureza experimental, logo os dados coletados são quantitativos (Pereira et al., 2018). 


\section{1 Área de estudo}

O estudo etnoherpetológico foi desenvolvido na cidade de General Carneiro, Paraná, coordenadas centrais

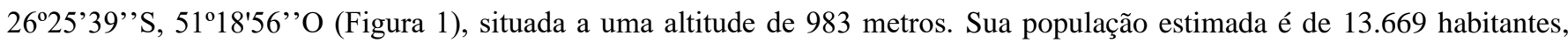
correspondendo a 12,76 indivíduos por quilômetro quadrado, com uma taxa de analfabetismo de 1,23(\%) na classe etária de 15 a 19 anos, 10,77(\%) de 40 a 49 anos e 22,7(\%) em cidadãos com mais de 50 anos de idade (IBGE, 2010).

Figura 1: Mapa da Área de Estudo.

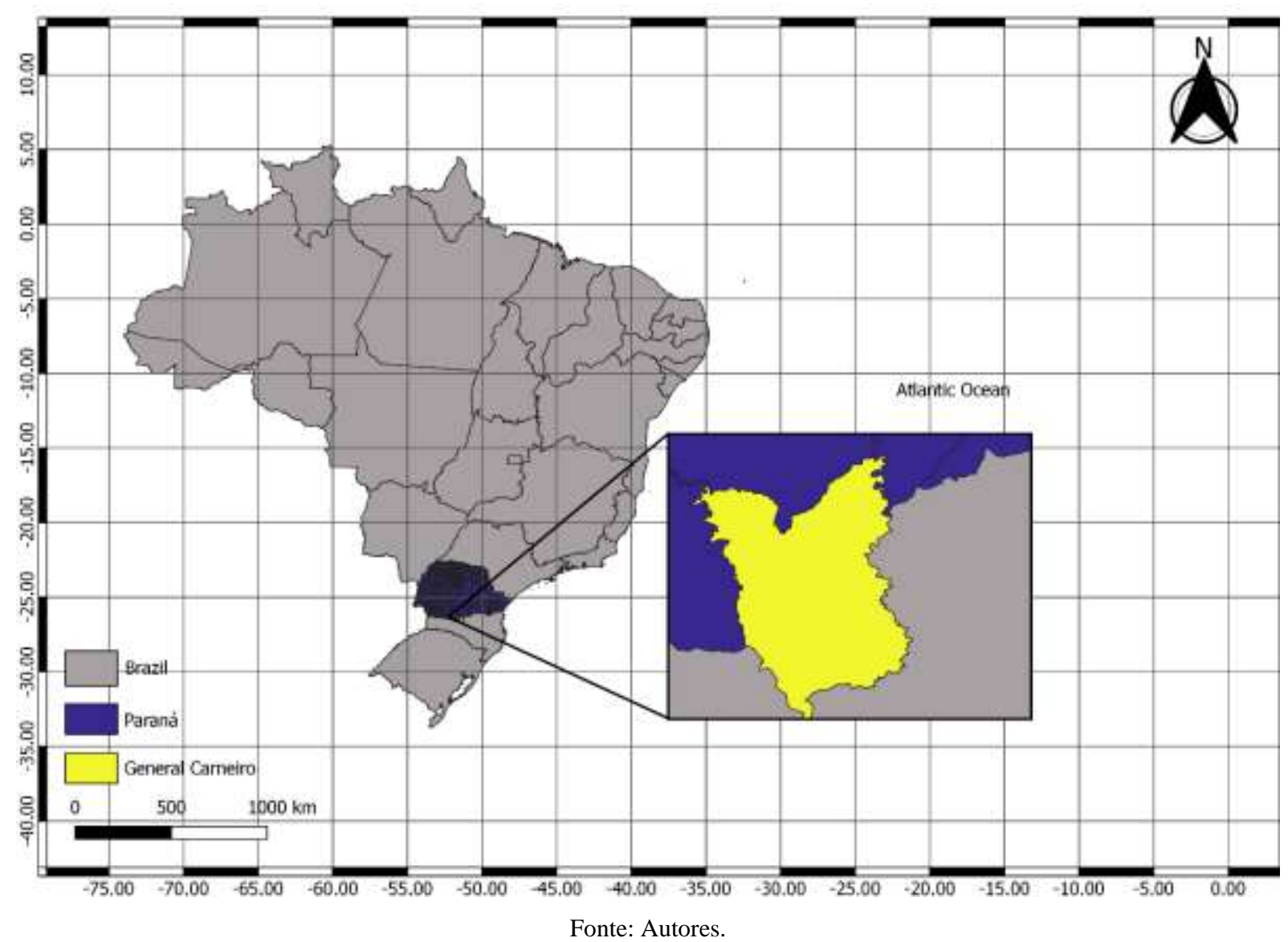

O Índice de Desenvolvimento da Educação Básica do Município (IDEB) 2017 não atingiu a meta para o município, a qual era 5,8 (IDEB, 2017) conforme mostra a Tabela 1.

Tabela 1. Índice de desenvolvimento da educação básica (IDEB) - 2017

\begin{tabular}{llll}
\hline Tipo de ensino & Municipal & Estadual & Público \\
\hline Fundamental & & - & - \\
Anos iniciais $\left(4^{\mathrm{a}}\right.$ série e/ou $5^{\circ}$ ano) & 5,4 & - & 5,4 \\
Anos finais $\left(8^{\mathrm{a}}\right.$ série e/ou $9^{\circ}$ ano) & - & 4,0 & 4,0 \\
Médio & - & 2,9 & 2,9 \\
\hline
\end{tabular}

\subsection{Geração de dados}

Fonte: IDEB (2017).

A amostragem representa diferentes gerações com um intervalo de 20 anos entre cada uma: geração $Z$ aqueles que nasceram entre 1994 e 2009, geração X nascidos entre 1965 e 1978, e a geração dos Boomers que vai de 1946 a 1964 
(Coworking, 2018). A geração de dados foi realizada no primeiro semestre de 2018, com 30 pessoas de cada faixa etária compreendidas entre 15 a 20 anos (geração Z), 40 a 45 anos (geração X) e pessoas com mais de 65 anos (geração dos Boomers).

A geração de dados foi realizada com indivíduos que compreendem as faixas etárias dentro das três gerações, sendo obtidos em eventos culturais em locais como praças e através de visitas domiciliares, tentando manter a aleatoriedade. Dessa forma, as amostras foram coletadas por quotas, onde o indivíduo é escolhido de acordo com as características determinadas pela pesquisa (Vieira, 2008). As características escolhidas foram três faixas de idades especificas. As pessoas abordadas responderam uma lista de dozes questões fechadas, baseadas em tópicos mencionados anteriormente (Santos, 1994).

\subsection{Análise dos Dados}

Os dados coletados foram organizados em tabela, contabilizados e analisados através de estatística descritiva. Por meio das frequências foi organizado um gráfico comparativo do nível de escolaridade em cada uma das faixas etárias. Os níveis de escolaridades foram definidos em: (a) sem escolaridade (instrução formal ausente); (b) ensino fundamental anos iniciais (até $4^{\mathrm{a}}$ série e/ou $5^{\circ}$ ano); (c) ensino fundamental anos finais (até $8^{\mathrm{a}}$ série e/ou $9^{\circ}$ ano); (d) ensino médio e(e) ensino superior, onde foi levado em consideração se o entrevistado tinha atingido alguma delas, não necessariamente completado o curso.

Para testar se há influência do grau de escolaridade na aceitação de crendices e mitos por diferentes gerações, foi analisada a proporção de respostas corretas para cada pergunta e analisada em frequência relativa. Por não apresentar normalidade dos dados, foi utilizado um teste não paramétrico de Kruskal-Wallis, o qual pode ser usado para comparar várias amostras independentes (Theodorsson-Norheim, 1986). Posteriormente, foi aplicado o teste posteriori de Mann-Whitney pairwise para verificar se havia diferença estatísticas entre os grupos analisados.

\section{Resultados e Discussão}

\subsection{Nível de escolarização}

As escolaridades que apresentaram maior frequência de acertos dentro das gerações dos entrevistados estão detalhadas na (Figura 2a). Dos entrevistados, obteve-se uma maior frequência do ensino médio seguido dos anos iniciais e uma menor frequência de ensino superior seguido de sem escolaridade. A faixa etária I (15- 20 anos) apresentou maior índice de escolaridade com maioria do ensino médio, a faixa etária III apresentou menor nível de escolaridade com maioria do ensino fundamental anos iniciais, seguido do ensino fundamental anos finais. Estes dados corroboram índices do IBGE (2010), que apontavam um índice gradativo de analfabetismo entre as faixas etárias, portanto diferenças de escolaridade entre as idades, sendo as mais jovens (acima de 15 anos) as que apresentam o maior número de indivíduos alfabetizados.

Com a aplicação do teste de Kruskal-Wallis, a hipótese de que a aceitação das crendices entre as gerações está diminuindo foi corroborada. Obteve-se uma diferença significativa entre as medianas da amostra (diferentes faixas etárias) analisadas $\left(\mathrm{KW}^{2}=24,31_{[\mathrm{Hc}=27,7] ;} \mathrm{P}<0,001\right)$. O resultado funcional dentro deste contexto indica que indivíduos com maior grau de escolaridade, possuem conhecimento cientifico sobre anfíbios e répteis mais adequado do que indivíduos com menor grau de escolaridade (Figura 2b). O teste posteriori de Mann-Whitney pairwise demonstrou que houve diferença estatística entre todas as faixas etárias. Portanto, os resultados estatísticos comprovam que existe uma diferença significativa no aceitamento dos mitos e crendices entre as gerações, onde as gerações mais atuais, que possuem também maior nível de escolaridade, apresentam conhecimento mais elevado a respeito desses animais.

$\mathrm{Na}$ aplicação do teste de Kruskal-Wallis para verificar se existe diferença significativa na influência do número de acerto sem relação aos graus de escolaridade, obteve-se que o grau de escolaridade mais alto possui níveis de acertos 
estatisticamente maiores $\left(\mathrm{KW}^{2}=27,48_{[\mathrm{Hc}=27,7] ;} \mathrm{P}<0,001\right.$; Figura 2c). Situação semelhante foi encontrada no estado de Minas Gerais, onde estudantes do ensino de ensino médio demonstraram maior conhecimento etnoherpetológico em relação aos estudantes do ensino fundamental (Dias et al., 2018). Um fato que pode justificar essa diferença é que indivíduos com ensino médio tenham estudado conteúdos sobre a herpetofauna por mais de uma vez durante sua trajetória escolar (Dias et al., 2018).

Figura 2. Gráfico com as classes de escolaridade e o número de pessoas para cada faixa etária (a). Diferenças estatísticas entre as três faixas etárias. Letras diferentes representam grupos estatisticamente diferentes (b). Diferença estatística comparando o número médio de acertos entre os níveis de escolaridade (c). A marcação (*) representa um conjunto que difere do conjunto anterior (b). Entretanto, optou-se por manter uma marcação diferenciada em função do baixo número de repetições (n=3).
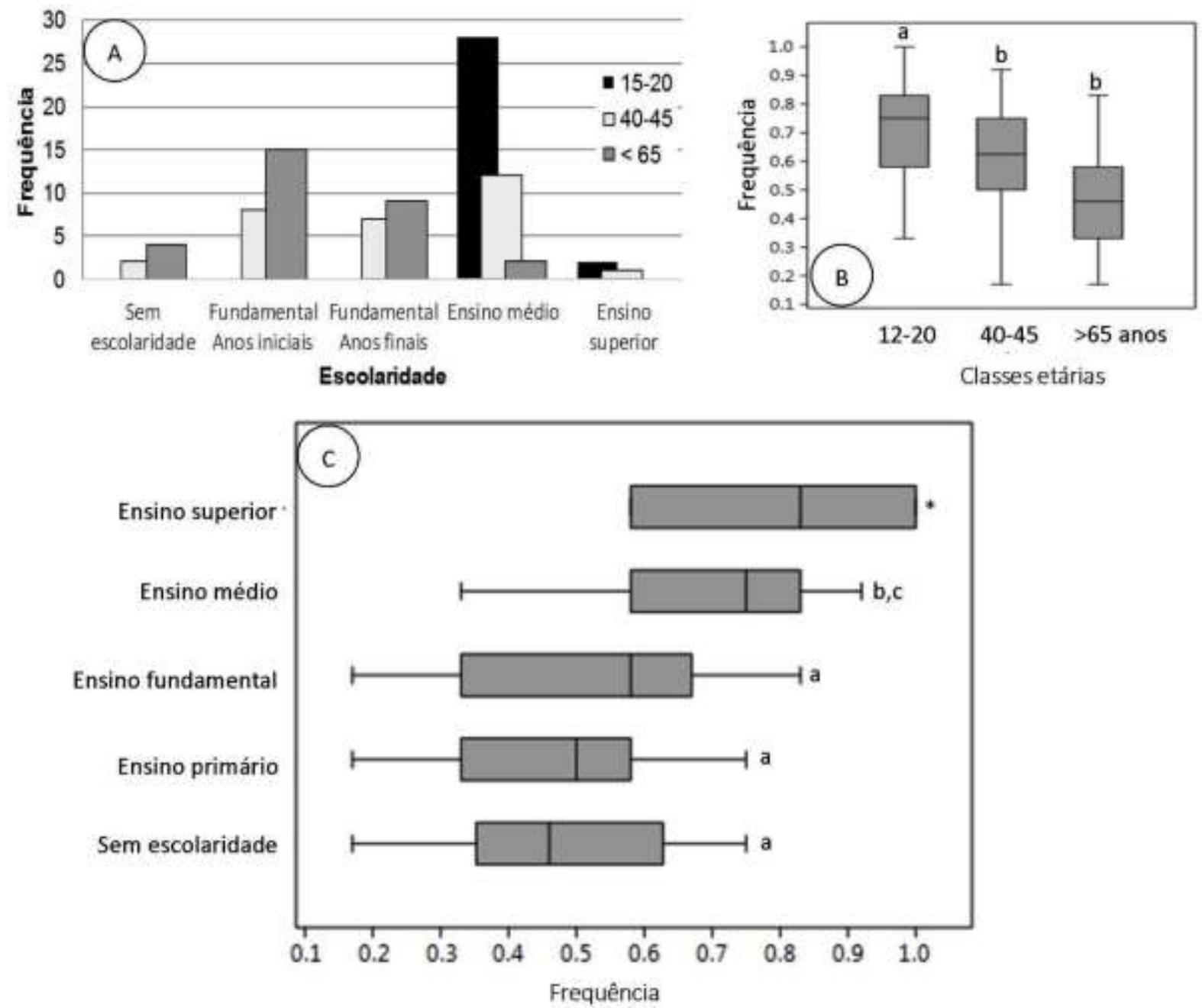

Fonte: Autores.

\subsection{Mitos e crendices}

No presente trabalho, a aceitação da maioria dos mitos e crendices foi maior nas faixas etárias III (acima de 65 anos) e II (40-45 anos) respectivamente, e obteve-se maior negação na faixa etária I (15-20 anos) como demonstrado na (Tabela 2). Apenas a pergunta dois teve uma porcentagem maior de acertos pela faixa etária III e a pergunta sete pela classe etária II. 
Tabela 2. Resultado percentual das perguntas feitas através dos questionários demonstrando o percentual de acerto.

\begin{tabular}{|c|c|c|c|}
\hline \multirow[t]{3}{*}{ Perguntas } & \multicolumn{3}{|c|}{ Faixas etárias: } \\
\hline & I & II & III \\
\hline & \multicolumn{3}{|c|}{ Acertos (\%) } \\
\hline 1.Todas as cobras são perigosas? & $80 \%$ & $67 \%$ & $60 \%$ \\
\hline 2. As cobras vivem em grupo? & $67 \%$ & $50 \%$ & $77 \%$ \\
\hline 3. As cobras mamam? & $80 \%$ & $60 \%$ & $40 \%$ \\
\hline 4. As cobras deixam o seu veneno em uma folha para atravessar um rio? & $97 \%$ & $93 \%$ & $70 \%$ \\
\hline 5. Cada anel do guizo corresponde a um ano de vida da cobra Cascavel? & $57 \%$ & $37 \%$ & $7 \%$ \\
\hline 6. As cobras hipnotizam as suas vítimas? & $63 \%$ & $40 \%$ & $0 \%$ \\
\hline $\begin{array}{l}\text { 7. Os "espinhos" (vertebras) de uma cobra morta contém veneno e se a } \\
\text { pessoa pisar nele pode se envenenar? }\end{array}$ & $40 \%$ & $43 \%$ & $23 \%$ \\
\hline 8. Se tocar em um sapo dá cobreiro? & $53 \%$ & $47 \%$ & $23 \%$ \\
\hline 9. Os sapos deixam germes dos cobreiros por onde passam? & $77 \%$ & $70 \%$ & $67 \%$ \\
\hline 10. A urina do sapo pode deixar uma pessoa cega? & $67 \%$ & $40 \%$ & $20 \%$ \\
\hline 11. As plantas que os sapos encostam ficam envenenadas? & $90 \%$ & $90 \%$ & $80 \%$ \\
\hline 12. Sapos no quintal são mandados? & $97 \%$ & $90 \%$ & $93 \%$ \\
\hline
\end{tabular}

Fonte: Autores.

Quando questionados se “todas as cobras são perigosas (pergunta 1)?”. Os mais jovens apresentaram um maior conhecimento afirmando que não, seguido da faixa etária II. Estes resultados corroboram os resultados encontrados para alunos do nordeste brasileiro (Alves et al., 2014), no entanto discordam de estudos mais antigos (Alves et al., 2012a; Alves et al., 2012b; Moura et al., 2010). Os resultados apresentados no presente estudo em associação com aquilo que é descrito na literatura, sugerem que há uma evolução no conhecimento herpetológico de estudantes mais novos em relação aos seus congêneres mais velhos, no que diz respeito à correta identificação de cobras peçonhentas. Sabe-se que a grande maioria dos ofídios não é peçonhenta, do total de 371 espécies de serpentes registradas para o Brasil até o início da década passada (2010), apenas 55 espécies eram consideradas peçonhentas e poderiam causar envenenamentos em humanos (Bérnils \& Costa 2012). Tal crença que todas as cobras são perigosas geram maiores taxas na intenção de atropelamentos em estadas Brasileiras (Beckmann \& Shine, 2012; Turci \& Bernarde, 2009; Secco et al., 2014). Levando em consideração que motoristas são pessoas mais velhas, isso é outro indicio que pessoas mais novas são mais inclinadas a negar que todas as cobras são venenosas.

Na pergunta 2 "as cobras vivem em grupo?”. A faixa etária III obteve uma porcentagem superior de acerto comparado com as mais jovens. Compreendendo que as serpentes vivem de forma solitária na natureza, encontrando-se apenas no ato de reprodução e ninhais. O mesmo não ocorreu em um estudo realizado Lauvers \& Mônico (2015), onde dos 46 entrevistados 45 confirmavam a crendice.

Na questão 3 "as cobras mamam?”. A negação da crendice ocorreu de forma gradativa da faixa etária I para a III. Nesse sentido, embora haja uma diminuição gradativa desta crendice na sociedade, ela ainda permanece aceita, principalmente entre os mais velhos, como relatado anteriormente (Foerster et al., 2013; De Maria et al., 2018). Segundo Fernandes-Ferreira et al. (2011), não há nenhuma serpente que possua o hábito de ingerir leite, pois não faz parte de sua dieta, além disso, o exercício de sucção não é possível devido à ausência do músculo esfíncter bucal.

Uma das crendices mais antigas foi apresentada na pergunta 4 "as cobras deixam o seu veneno em uma folha para atravessar um rio?". Tal pergunta teve uma porcentagem relevante de acerto nos três grupos (97\% I, 93\% II e 70\% III). Esse resultado discorda de um estudo recente (De Maria et al., 2018) em que 66\% dos estudantes do ensino fundamental da Paraíba (i.e., 209 de 313) dos entrevistados acreditavam nessa crendice.

Quando perguntado se: “cada anel do guizo corresponde a um ano de vida da cobra Cascavel (pergunta 5)?”, apenas $7 \%$ da faixa etária III respondeu corretamente, com 37\% para II e 57\% para III. Entretanto, sabe-se que não existe relação entre 
o guizo e a idade da serpente, cada anel consiste em resquícios de uma troca de pele, evento que pode acontecer várias vezes durante o ano (Melgarejo, 2003).

A única pergunta onde não teve nenhum acerto na faixa etária III foi se "as cobras hipnotizam as suas vítimas?". No entanto, sabe-se que as presas ficam imóveis como instinto de defesa. Este pensamento possivelmente tem sua origem na falsa impressão causada pelo olhar fixo das serpentes devido à ausência de pálpebras móveis e à mobilidade limitada do globo ocular (Schroeder, 2013; Hickman et al., 2016).

Na pergunta 7 “As vertebras de uma cobra morta contém veneno e se a pessoa pisar nele pode se envenenar?”, a faixa etária II se destacou com um maior número de acertos, seguido da faixa etária III. As serpentes peçonhentas possuem veneno armazenado apenas em glândulas localizadas na região bucal, o qual escorre através de presas inoculadoras, sendo assim, o contato com vértebras e costelas está completamente livre de perigo quanto a riscos de envenenamento (Fernandes-Ferreira et al., 2011).

Na pergunta 8 relacionada aos sapos, "se tocar em um sapo da cobreiro?" se obteve uma média baixa de acertos, sendo $53 \%$ na faixa etária I, $47 \%$ na II e apenas $23 \%$ na III. Já na questão 9 "os sapos deixam germes dos cobreiros por onde passam?" houve um aumento da porcentagem de acertos nas três gerações. No passado com pouco acesso a informação, o cobreiro ou herpes-zoster, uma doença viral causada pelo mesmo vírus da catapora, era atribuída os anfíbios anuros, mas não possuem qualquer relação (Luchese, 2013).

A pergunta 10 "a urina do sapo pode deixar uma pessoa cega?" obteve diferenças entre respostas em um padrão decrescente entre os grupos, sendo que na faixa etária I predominou maior número de acertos. Contudo, sabe-se que estes animais não contêm nenhuma substância tóxica na urina que possa causar a cegueira, sendo a mesma liberada apenas em situações de estresse, como mecanismo de defesa frente a predadores ou alguma outra ameaça (Dias et al., 2018).

Para a pergunta 11 "as plantas que os sapos encostam ficam envenenadas?" foi obtido equilíbrio na proporção de acertos entre as faixas etárias, demostrando que as diferentes classes compreendem que esses animais não causam envenenamentos em plantas, assim como na questão 12 "Sapos no quintal são mandados?" se obteve um alto nível de acertos de todas as faixas etárias.

Portanto, os dados demonstrados na Tabela 2, revelam que entre três das gerações atuais (pais, filhos e netos) ainda são aceitas as crendices e o conhecimento popular. Nesse contexto, as informações errôneas que a população apresenta sobre determinado grupo animal, podem levar à mortalidade desses animais (Moura et al., 2010; Santos, 2010; Secco et al., 2014). As crenças e mitos antigos ainda permeiam a população e essas informações equivocadas continuam sendo passadas de geração à geração, porém a escolaridade está atuando como um fator positivo na diminuição da aceitação desses conhecimentos errôneos (De Maria et al., 2018).

Neste aspecto, um dos fatores que pode contribuir para um aumento no conhecimento da herpetofauna é a presença de aulas práticas nas escolas e a possibilidade de contato de estudantes com as espécies de anfíbios e répteis, o que resultaria em um conhecimento maior sobre aspectos da ecologia e biologia (Luchese, 2013). O ensino de Ciências tem grande influência na formação integral do cidadão, como ser pensante, atuante e como contribuinte para o futuro da sociedade (Filho et al., 2011). Sendo assim, o ensino da zoologia, presente no ensino fundamental e ensino médio tem grande importância na compreensão do mundo animal, influenciando estudantes na preservação da biodiversidade faunística (Santos \& Terán, 2013). Portanto, a escolaridade tem uma forte relação na quebra dos mitos crendices. Conhecimentos científicos abordados nas escolas de forma correta podem ser a chave para abrir o caminho da melhor convivência, transformando o senso comum, em saber elaborado/ científico, visando melhor interação e a preservação desses animais (Costa et al., 2017). 


\section{Considerações Finais}

Neste contexto, as crenças antigas e mitos populares ainda estão presentes nos munícipes de General Carneiro, e essas informações continuam sendo passadas de geração a geração, porém com redução de intensidade, tendo em vista que houve uma variação desse conhecimento entre as gerações, com maior taxa de conhecimento correto nas gerações atuais, refletindo em uma maior compreensão de instrução cientifica sobre anfíbios e répteis corroborando com a hipótese previamente designada. Outro fator relevante foi o grau de escolaridade, influenciando positivamente, de modo que as pessoas que possuem um nível de escolaridade maior têm maior entendimento sobre os processos científicos naturais que envolvem a herpetofauna.

Estudos futuros poderão explorar a interação entre escolaridade com tempo longe da escola, afim de verificar se a idade é um fator preponderante mesmo que o indivíduo possua escolaridade superior (i.e., graduação).

\section{Referências}

Alves, R. R. N., Gonçalves, M. B. R. \& Vieira, W. L. S. (2012a) Caça, uso e conservação de vertebrados no semiárido Brasileiro. Tropical Conservation Science, 5(3), 394-416.

Alves, R. R. N., Vieira, K. S., Santana, G. G., Vieira, W. L. S., Almeida, W. O., Souto W. M. S., Montenegro, P. F. G. P. \& Pezzuti, J. C. B. (2012b). A review on human attitudes towards reptiles in Brazil. Environmental Monitoring and Assessment, 184 (11), $6877-6901$.

Alves, R. R., Silva, V. N., Trovão, D. M., Oliveira, J. V., Mourão, J. S., Dias, T. L., Alves, Â. G., Lucena, R. F., Barboza, R. R., Montenegro, P. F., Vieira, W. L. \& Souto, W. M. (2014). Students' attitudes toward and knowledge about snakes in the semiarid region of Northeastern Brazil. Journal of Ethnobiology and Ethnomedicine 10, 1-30

Alves, R. R. N. 2017. “Ethnozoology.” In: The International Encyclopedia of Primatology, 2p.

Alves, R. R. N. \& Silva-Souto, W. M. (2015). Ethnozoology: A Brief Introduction. Ethnobiology and Conservation, 4 (1), 1-13.

Alves R. R. N., Silva J. S., da Silva-Chaves L. \& Albuquerque U. P. (2018). Ethnozoology and animal conservation. Ethnozoology: Elsevier, 15p.

Beckmann, C. \& Shine, R. 2012. Do drivers intentionally target wildlife on roads? Austral Ecology 37 (5), 629-632.

Bérnils, R. S. \& H. C. Costa (org.). 2012. Brazilian reptiles: List of species. Version 2012.1. <http://www.sbherpetologia.org.br/>. Sociedade Brasileira de Herpetologia.

Coworking, $2018<$ https://coworkingbrasil.org/news/diferencas-entre-geracoes/>.

Cardoso, C. C., Rebelato, M. M., Ferreira D. L., Marinho, B. C. J., Sorares, S. C. \& Sartori, J. (2010). Análise etnoherpetológica acerca das serpentes: influência no ensino de Biologia. In: RESUMOS DA XI SALÃO DE INICIAÇÃO CIENTÍFICA PUCRS,2010, Rio Grande do Sul, Anais...

Costa, C. D. P. \& Cruz, G. L. (2017) Educação Ambiental no Centro de Apoio e Reintegração da Criança e do Adolescente (CARCA) do município de Ivinhema (MS): conhecimentos e ferramentas de aprendizagem sobre as serpentes. In: RESUMOS DA IX ENCONTRO PESQUISA EM EDUCAÇÃO AMBIENTAL, Anais...

Crespo, E. G. (2012) Anfíbios E Répteis, 2012. <http://luisbravo.net/spherpetologia/art_crespo01.htm>.

De Maria, D. L., Abrantes, R. M. M. \& Abrantes, F. H. S. (2018). A Zoologia No Contexto Escolar: O Conhecimento De Alunos E Professores Sobre A Classe Reptilia E A Utilização De Atividade Lúdica Na Educação Básica. Revista Experiências em Ensino de Ciências, Mato Grosso, 13 (4), $367-392$.

Dias, M. A. S., Lima, B. N. \& Figueiredo-de-Andrade A. C. (2018). Análise Do Conhecimento Etno-Herpetológico Dos Estudantes No Município De Salinas, Minas Gerais, Brasil. Revista Acta Biomedica Brasiliensia, 9 (1), 36-47.

Fernandes-Ferreira, H., Cruz L. R., Borges-Nojosa, M. D. \& Alves, N. R. R. (2011). Crenças associadas a serpentes no estado do Ceará, Nordeste do Brasil. Revista Sitientibus: Série Ciências Biológicas, Bahia, 2 (11),153-163.

Filho, A. B. S., Santana, S. R. J. \& Campos, D. T. (2011). O ensino de ciências naturais nas séries/anos iniciais do ensino fundamental. In: Resumos Do V Colóquio Internacional, Educação E Contemporaneidade, Anais...

Foerster, S. A. I., Bezerra, P. E. S. \& Almeida, C. G. (2013). A obra-preta na percepção dos moradores da Fazenda Saco, Pernambuco. In: Resumos DAI CONICBIO / II CONABIO / VI Simcbio Biodiversidade E Água: Desafios E Cooperação, Anais...

Hickman C. P. J. R., Roberts, S. L., Keen, L. S., Eisenhour, J. D., Larson, A. \& I'anson, H. (2016) Princípios integrados de zoologia. Guanabara Koogan, 1405 p.

IBGE, 2010. <https://cidades.ibge.gov.br/v4/brasil/pr/general-carneiro/panorama>.

IDEB, 2017. <https://www.qedu.org.br/cidade/3294-general-carneiro/ideb?dependence=5\&grade=2\&edition=2017> . 
Research, Society and Development, v. 10, n. 10, e482101019140, 2021

(CC BY 4.0) | ISSN 2525-3409 | DOI: http://dx.doi.org/10.33448/rsd-v10i10.19140

Lauvers, W. D. \& Mônico, A. T. (2015) A Etnozoologia E O Comportamento Social De Xenodon Neuwiedii (Squamata, Colubridae) No Sudeste Do Brasil: Um Estudo De Caso. In: Resumos Do XII Congresso De Ecologia Do Brasil, Anais...

Luchese, M. S. (2013). A Herpetologia no Ensino Fundamental: O que os alunos pensam e aprendem, 54 f. Trabalho de Conclusão de Curso (Graduação em Ciências Biológicas) - Universidade Federal do Rio Grande do Sul, 2013.

Melgarejo, A. R. Serpentes peçonhentas do Brasil. (2003). Animais Peçonhentos no Brasil. Biologia, clínica e terapêutica dos acidentes. Sarvier, FAPESP, $28 \mathrm{p}$.

Moura M. R., Costa, H. C., São-Pedro, V. A., Fernandes, V. D. \& Feio, R. N. (2010). O relacionamento entre pessoas e serpentes no leste de Minas Gerais, sudeste do Brasil. Revista Biota Neotropica, 10 (4), 133-142.

Mourão, J. S. \& Nordi, N. (2006). Pescadores, peixes, espaço tempo: uma abordagem etnoecológica. Revista Interciencia, 31 (5), 358-363.

Pereira, A. S., Shitsuka, D. M., Parreira, F. J., \& Shitsuka, R. (2018). Metodologia da Pesquisa Cientifica. UFSM. https://repositorio.ufsm.br/bitstream/handle.

Santos D. C. S. \& Terán A. F. (2013). Condições De Ensino Em Zoologia No Nível Fundamental: O Caso Das Escolas Municipais De Manaus-AM. Revista Amazônica de Ensino de Ciências, 6 (10), 01-18

Santos E. (1994). Zoologia Brasilica: Anfibios e Répteis. Villa Rica, 263p.

Santos, S. C. S. (2010). Diagnóstico e possibilidades para o ensino de zoologia em Manaus/AM. 237f. Dissertação (Mestre em Ensino de Ciências) Universidade do Estado do Amazonas escola normal superior. Manaus, 2010.

Schroeder, E. Os Conceitos Espontâneos Dos Estudantes Como Referencial Para O Planejamento De Aulas De Ciências: Análise De Uma Experiência Didática Para O Estudo Dos Répteis A Partir Da Teoria Histórico Cultural Do Desenvolvimento (2013). Revista Experiências em Ensino de Ciências, 8 (1), 130-144.

Secco, H., Ratton, P., Castro, E., da Lucas, P. S. \& Bager, A. (2014). Intentional Snake Road-Kill: A Case Study using Fake Snakes on a Brazilian Road. Tropical Conservation Science 7 (3), 561-571.

Sturtevant, W. C. (1964). Studies in Ethnoscience. American Anthropologist 66 (3), 99-131.

Theodorsson-Norheim, E. (1986). Kruskal-Wallis test: BASIC computer program to performnonparametric one-way analysis of variance and multiplecomparisons on ranks of several independent samples. Computer Methods and Programs in Biomedicine, 23 (1), 57-62.

Turci, L. C. B. \& Bernarde, P. S. 2009. Vertebrados atropelados na Rodovia Estadual 383 em Rondônia, Brasil. Biotemas 22(1), 121-127.

Vieira S. (2011). Introdução à bioestatística. Elsevier, 2011. 345p.

Werner, O. (1972). "Ethnoscience 1972". Annual Review of Anthropology 1, 271-308. 